\title{
Predictors of Loss to Follow-up in Patients on Antiretroviral Treatment in Centre Hospitalier Essos, Cameroon
}

\author{
Agbornkwai Nyenty Agbor ${ }^{*}$, Bita Andre Izacar Gael, Ajong Brian ${ }^{1}$, Ateh Stanislas ${ }^{1}$, \\ MabounaAmatangana Stephane ${ }^{1}$, Ismaila Esa ${ }^{3}$, Awa Cynthia ${ }^{3}$, Xavier Tchetnya ${ }^{1}$ and \\ Nwokedi Austin Ndulue 4
}

${ }^{1}$ Ministry of Public Health, Cameroon

${ }^{2}$ Hellen Keller International, Cameroon

${ }^{3}$ Cameroon Baptist Convention Health Board, Cameroon

${ }^{4}$ Consultant, Nigeria

\begin{abstract}
Background: HIV remains one of the major public health issues in Cameroon. Progress has been made in attaining the 9090-90 according to the UNAIDS target, the Loss to follow-up (LTFU) remains a significant challenge to attain the second and third 90. There is a gap of information concerning assessing predictors and determinants of LTFU in the Cameroonian setting taking into consideration psychosocial, economic, cultural, financial, and treatment-related factors. This study seeks to assess and evaluate the determinants and predictors of LTFU among patients enrolled for treatment in the Centre Hospitalier Essos (CHE), Cameroon.

Methods: We carried out a retrospective case-control study among 200 patients from which, 100 cases of patients LTFU and 100 controls of regular patients from the treatment centre. Simple random sampling was used to select 100 participants from the case list and matched with 100 participants from the control list. We compared several demographic, social, disease-related, and treatment-related characteristics of the two groups to determine which properties are significantly associated with LTFU. Data analysis was done using the SPSS software. Bivariate and multivariate analysis was done with $\mathrm{p}$ value $<0.05$, odds ratio $95 \% \mathrm{Cl}$.

Results: Out of 200 participants, the mean age was $38 \pm 9$ years. A total of 74 (37\%) participants' HIV status was known by a family member. About $50 \%$ (54) of those who were married had an HIV-positive partner and of these, $86 \%$ (46) were on treatment. On multivariate analysis, distance to health facility; occurrence of opportunistic infections; patient receiving treatment for other conditions; duration of psychological follow-up and number of adherence counselling sessions were found to be independently associated with loss to follow-up.

Conclusion: With LTFU, there is a consequent increased risk of HIV transmission and also increased morbidity and mortality. Reinforcement of adherence counseling sessions, intensification of patient tracking especially for patients with comorbidities, transfer of patients in suburbs to health facilities closer to their areas of residence will be important to curb LTFU rates and improve on retention of patients LTFU.
\end{abstract}

\section{Introduction}

One of the most difficult problems to resolve for public health in general and infectious diseases, in particular, has been the Human immunodeficiency virus infection and acquired immunodeficiency syndrome (HIV/AIDS) pandemic. According to United Nations Programme on HIV/ AIDS (UNAIDS), about 36.9 million people are living with HIV worldwide [1]. Amongst these, $75 \%$ are aware of their status and 21.7 million (59\%) are on antiretroviral therapy (ART). More than $51 \%$ of AIDS-related deaths were averted between 2004 and 2017 due to the use of ART [1]. The use of antiretroviral medication has revolutionized HIV/AIDS

*Corresponding author: Agbornkwai Nyenty Agbor, Ministry of Public Health, Cameroon, Tel: +237674505616

Accepted: June 18, 2021

Published online: June 21, 2021

Citation: Agbor AN, Gael BAI, Brian A, et al. (2021) Predictors of Loss to Follow-up in Patients on Antiretroviral Treatment in Centre Hospitalier Essos, Cameroon. Clin J HIV AIDS 5(1):62-69 
management. ARTs are responsible for the transformation of HIV/AIDS into a chronic infectious disease when they are taken as prescribed.

Initiation to ARTs has several effects which include increased life expectancy and overall improved standard of living, but this entails a lifelong follow-up of prescription protocols and scheduled clinical visits at various health centers. However, despite a large proportion of HIV-infected patients on treatment, up to $8-16 \%$ of patients die within the first year of ART treatment in sub-Saharan Africa as reported by Lawn and colleagues in 2008 [2]. One of the challenges to successful implementation and use of ART has been the loss to follow-up (LTFU) of patients already on treatment and this contributes significantly to higher mortality rates in this group of patients compared to that adherent to treatment (Fox and Rosen, 2010).

HIV/AIDS is one of the main health issues in Cameroon. With a population of about 18 million people, the national prevalence of HIV/AIDS in Cameroon stands at 3.7\% [3]. This is a relatively low prevalence compared to previous years and this is as a result of several efforts made by the Ministry of Public health which include: harmonization of treatment nationwide with the establishment of a treatment guideline; increased accessibility to ART (ART are free of charge in Cameroon since 2007); HIV/AIDS declared a national priority and setting up of a National AIDS control committee. Furthermore, the coverage of ARVs has steadily improved from $36.5 \%$ (2010) to $49.6 \%$ (2017) of positive patients and almost $90 \%$ of patients with a known HIV positive status on treatment [3]. Nonetheless, in 2010, a special HIV Drug Resistance Group reported up to $33 \%$ of patients on treatment were lost to followup [4]. This remains a dilemma as access to ARTs has been improved significantly in Cameroon with the elimination of treatment cost, the duplicity of treatment centers, adoption of the 'test and treat' guidelines, and training of health care providers. The other important component of the problem is patient-centered and requires compliance and adherence to treatment as well as the respect of scheduled pick-up visits to the various health centers responsible for ART dispensation. This engages the responsibility of the patient to be engaged in effective consumption of their ARTs and effective followup at their various treatment units. Several factors have been highlighted and earmarked from several studies as responsible for LTFU and these include late ARV initiation, long-distance from initiation sites, tuberculosis and HIV coinfection, and increased cost of treatment [5-9]. However, there is a gap of information concerning assessing predictors and determinants of LTFU in the Cameroonian setting taking into consideration psychosocial, economic, cultural, financial, and treatment-related factors. This study seeks to assess and evaluate the determinants and predictors of LTFU among patients enrolled for treatment in the Centre Hospitalier Essos, Cameroon.

\section{Materials and Methods}

\section{Study design}

The study was a retrospective case-control study. Treatment Charts or Patient Files of HIV patients enrolled in the treatment center of the Centre Hospitalier Essos between January 2007 and January 2017 were assessed.

\section{Study site}

The study was conducted in the Centre Hospitalier Essos, in the Centre Region of Cameroon. It is a $2^{\text {nd }}$ level hospital providing care to the large population of the Djoungolo Health District of the Centre Region of Cameroon.

\section{Sample design}

Eligible study subjects were identified, and line listed using their ART clinic registration codes, cases on one list, and controls on another list. Using Excel ${ }^{\circledR}, 100$ participants (cases) were randomly selected from the case list. Random sampling is the sampling technique in which each participant has an equal probability of being chosen. Matching for age and sex was done from the controls list. Wherever there was more than 1 participant who matched (for a particular case) from the controls list, the ART numbers of such participants were input in Excel $^{\circledR}$ and a random ranking done, and the first ranked participant was used as the definitive control participant for that case.

\section{Sampling}

The sample size was calculated using the following assumptions for a matched case-control design: 95\% confidence interval, 1:1 ratio of cases to controls, 1 odds ratio. This gives an estimated sample size of 200 participants, 100 cases, and 100 controls using the OpenEpi ${ }^{\circledR}$ Version 3 sample size calculator [10].

\section{Study Participants}

The study population will be HIV-positive patients enrolled and receiving treatment in the HIV treatment centers of $\mathrm{CHE}$ between January 2007 and December 2017.

Inclusion criteria:

- HIV-positive patients who were recruited into the clinic cohort between January 2007 and December 2017.

- Patients more than 19-years of age

Exclusion criteria:

- Patients transferred out to another facility

- Patients who died less than 3 months after starting ARVs.

- Patients less than 19 years of age

\section{Data collection and data analysis}

The following tools were used for data collection: ART treatment registers and Individual patient records/files.

i. Socio-demographic characteristics: Gender, Age, telephone number, place of residence, occupation, employment status, income, insurance scheme, religion, alcohol, and tobacco consumption, educational level, matrimonial status, distance to treatment Center, Hospital waiting time, distance from home to hospital.

ii. Clinical features including date of HIV diagnosis, baseline weight, and height, clinical stage at presentation, ART side 
Citation: Agbor AN, Gael BAI, Brian A, et al. (2021) Predictors of Loss to Follow-up in Patients on Antiretroviral Treatment in Centre Hospitalier Essos, Cameroon. Clin J HIV AIDS 5(1):62-69

effects, Opportunistic infections, use of other treatment or other drugs.

iii. Treatment-related variables including Date of ART initiation, first-line ART used, drug side effects reported, HIV status of partner, viral load results, and other treatment.

iv. These variables were entered electronically and exported. Data analysis was done using SPSS software. Descriptive statistics for sociodemographic factors and clinical variables were estimated at baseline, including frequencies for categorical data as well as means and standard deviations for continuous variables. Furthermore, bivariate and multivariate analysis was done with $\mathrm{P}$-value $<0.05$, Odds ratio $95 \% \mathrm{Cl}$ not overlapping with 1 .

\section{Definitions}

- Loss to follow-up (Case): A patient was defined as lost to follow-up (case) if there was no contact for 90 days after the last missed appointment for ARV refill and fulfilled the inclusion criteria.

- Patients in care (Control) was defined as all patients who maintained contact with the treatment center and fulfilled the inclusion criteria (contact with hospital must be established between 0 to $<90$ days after last missed appointment for ARV refill).

\section{Ethical consideration}

Ethical clearance was obtained from the Institutional Review Board of the Centre Hospitalier Essos. Confidentiality and anonymity of patients were ensured by the use of only their case numbers for identification.

All data was stored and accessed only by the primary investigator and data entry was done only with patient codes.

\section{Results}

\section{Sociodemographic characteristics, patient environmental factors}

In our population of 200 participants (100 cases and 100 controls), the mean age was 38 9-years and their median monthly income (USD) was \$102.5.Most (71\%) of the participants were female, 123 patients (62\%) had completed secondary education, and $62 \%$ of participants were single. A total of 111 (56\%) participants were employed, 188 (94\%) were Christians, and 149 (75\%) consumed alcohol (Table 1). Generally, there was an average of $3 \pm 2$ persons per household. A total of 74 (37\%) participants status was known by a family member among cases and controls, (50.0\%) of those who were married had HIV+ partners and of these, $46(85.5 \%)$ were on treatment. The mean amount spent per health consultation was $\$ 7.3 \pm 17.7$ and the median distance to the health facility by a patient was $6.0(4.0-10.0) \mathrm{km}$.

The median duration (IQR) of psychosocial follow-up was 27 (16-41) months. The mean number of adherence counseling sessions was $4 \pm 2$, and a total of 60 (30.0\%) participants were enrolled in a support group.
Table 1: Socio-demographic and environmental characteristics ( $N=200)$

\begin{tabular}{|c|c|c|}
\hline Variables & Numbers & Percentage \\
\hline \multicolumn{3}{|l|}{ Gender } \\
\hline Male & 58 & 29 \\
\hline Female & 142 & 71 \\
\hline \multicolumn{3}{|l|}{ Level of education } \\
\hline None & 3 & 1.5 \\
\hline Primary & 25 & 12.5 \\
\hline Secondary & 123 & 61.5 \\
\hline Tertiary & 49 & 24.5 \\
\hline \multicolumn{3}{|l|}{ Marital status } \\
\hline Single (+divorced and widow) & 123 & 61.5 \\
\hline Married (+concubine) & 77 & 38.5 \\
\hline \multicolumn{3}{|l|}{ Occupation } \\
\hline Employed & 111 & 55.5 \\
\hline Unemployed & 89 & 44.5 \\
\hline \multicolumn{3}{|l|}{ Religion } \\
\hline Christian (press, Baptist, catholic, others) & 188 & 94 \\
\hline Muslim & 9 & 4.5 \\
\hline None & 3 & 1.5 \\
\hline \multicolumn{3}{|l|}{ Other variables } \\
\hline Health Insurance & 18 & 9 \\
\hline Alcohol intake & 149 & 74.5 \\
\hline Smoking & 15 & 7.5 \\
\hline \multicolumn{3}{|l|}{ Family information } \\
\hline Status is known by a family member & 74 & 37 \\
\hline Other family members HIV+ & 7 & 3.5 \\
\hline Mother & 4 & 57.1 \\
\hline Daughter & 2 & 28.6 \\
\hline Son & 1 & 14.3 \\
\hline \multicolumn{3}{|l|}{ Partner's status $(n=108)$} \\
\hline HIV+ & 54 & 50 \\
\hline $\mathrm{HIV}+$ on treatment & 46 & 85.5 \\
\hline Accessible patients & 186 & 93 \\
\hline
\end{tabular}

\section{Clinical factors at initiation and treatment history}

The majority, $165(82.5 \%)$ of patients were diagnosed during a clinical consultation, and 35 (17.5\%) were diagnosed during Voluntary Counseling and Testing (VCT). The most frequent criteria used for the initiation of clients to ART were the Cluster of differentiation (CD4) count (44.5\% of the participants), the clinical presentation at initiation/consultation (31.5\%), and the 'Test and Treat' approach (24.0\%). At diagnosis, most $(48 \%)$ of the participants were at WHO stage II, and $9.0 \%$ were initiated in WHO stage IV. The mean body mass index (BMI) of patients was $25.0 \pm 4.3 \mathrm{~kg} / \mathrm{m}^{2}$ and the median duration of follow-up was 45 months (27-80 IQR).

The majority (98.5\%) of the participants had been initiated at $\mathrm{CHE}$ (site of study) versus $1.5 \%$ (03) initiated in other health facilities. The median CD4 at the initiation of treatment was 298 cells $/ \mathrm{mm}^{3}$ (158-416). Out of 181 patients who had completed their first viral load test (VL) six months after initiation on ART, 75,1\% of them had a suppressed initial viral load result ( $\leq 1000$ copies $/ \mathrm{ml}$ ). Of the 11 patients who completed their $2^{\text {nd }} \mathrm{VL}, 45.5 \%$ had a VL $>1000$ copies $/ \mathrm{ml}$. At the time of this study, 197 (99\%) of participants were on first- 
Citation: Agbor AN, Gael BAI, Brian A, et al. (2021) Predictors of Loss to Follow-up in Patients on Antiretroviral Treatment in Centre Hospitalier Essos, Cameroon. Clin J HIV AIDS 5(1):62-69

line ARV and 78 (39\%) participants reported side effects from antiretroviral medication. Among the most reported side effects was Dizziness (37.2\%); Headaches (29.5\%) Nausea (28.2\%). while 25 (12.5\%) had suffered from an opportunistic infection, the most common opportunistic diseases were Herpes zoster (44.0\%) and tuberculosis (Table 2).

\section{Bivariate analysis}

On bivariate analysis: marital status, educational level, median monthly income, whether the patient's status was known by a family member, amount of money spent per consultation, distance to the health facility, and patient accessibility were found to be associated with loss to followup (Table 3).

Indeed, among the single participants, $69 \%$ of the patients were LTFU (OR-1,896; p-value-0.042); the proportion of patients with a family member who was informed of the patient's serological status were less (52\%) with an OR-0.260; p-value-0.0000. Patients who spend an average of $\$ 5.98 \pm 0.59$ are less likely to be LTFU compared to those who spend $\$ 8.54$ \pm 25.1 ( $p$-value-0.014). The results also show that the further the distance from the health facility, the greater the chance of being a loss to follow-up client. Averagely, a distance of 7.5

Table 2: Initiation and Treatment History ( $N=200)$

\begin{tabular}{|c|c|c|c|}
\hline Variable & Frequency & Percentage & Mean $\pm \mathrm{SD} /$ median (IQR) \\
\hline \multicolumn{4}{|l|}{ WHO stage at initiation } \\
\hline Stage I & 33 & 16.5 & \\
\hline Stage II & 96 & 48 & \\
\hline Stage III & 53 & 26.5 & \\
\hline Stage IV & 18 & 9 & \\
\hline \multicolumn{4}{|l|}{ Place of treatment initiation } \\
\hline Same health facility & 197 & 98.5 & \\
\hline Different health facility & 3 & 1.5 & \\
\hline Median CD4 at initiation (cells $/ \mathrm{mm}^{3}$ ) & & & $298(158-416)$ \\
\hline Median First viral load in copies/ml $(n=181)$ & & & $210(60-945)$ \\
\hline $0-40$ & 37 & 20.4 & \\
\hline $41-200$ & 53 & 29.3 & \\
\hline $201-1000$ & 46 & 25.4 & \\
\hline$>1000$ & 45 & 24.9 & \\
\hline Median Last viral load in copies/ml ( $n=11)$ & & & $300(40-2419)$ \\
\hline $0-40$ & 4 & 36.4 & \\
\hline $41-200$ & 1 & 9.1 & \\
\hline $201-1000$ & 1 & 9.1 & \\
\hline$>1000$ & 5 & 45.5 & \\
\hline First-line treatment & 197 & 98.5 & \\
\hline Second-line treatment & 3 & 1.5 & \\
\hline Mean Number of doses per day & & & $1 \pm 1$ \\
\hline Reported side effects & 78 & 39 & \\
\hline Dizziness & 29 & 37.2 & \\
\hline Nausea & 22 & 28.2 & \\
\hline Headaches & 23 & 29.5 & \\
\hline Fatigue & 15 & 19.2 & \\
\hline Skin rash & 2 & 2.5 & \\
\hline Somnolence & 3 & 3.8 & \\
\hline Insomnia & 11 & 14.1 & \\
\hline Opportunistic infections & 25 & 12.5 & \\
\hline Herpes Zoster & 11 & 44 & \\
\hline Tuberculosis & 9 & 36 & \\
\hline Oropharyngeal candidiasis & 4 & 16 & \\
\hline Toxoplasmosis & 2 & 8 & \\
\hline Other treatment & 29 & 14.5 & \\
\hline Anti TB & 5 & 17.2 & \\
\hline OCS & 6 & 20.7 & \\
\hline Anti-hypertensives & 4 & 13.8 & \\
\hline Anti-diabetics & 2 & 6.9 & \\
\hline Iron supplements & 1 & 3.4 & \\
\hline Traditional medication & 14 & 48.3 & \\
\hline
\end{tabular}


Citation: Agbor AN, Gael BAI, Brian A, et al. (2021) Predictors of Loss to Follow-up in Patients on Antiretroviral Treatment in Centre Hospitalier Essos, Cameroon. Clin J HIV AIDS 5(1):62-69

Table 3: Bivariate analysis of Socio-demographic, patient environment characteristics $(N=200)$

\begin{tabular}{|c|c|c|c|c|c|}
\hline Variable & LTFU (\%) & No LTFU (\%) & OR & $\% \mathrm{Cl}$ & P-value \\
\hline Age (mean $\pm S D)$ & $38 \pm 9$ & $39 \pm 10$ & & -5.304 & 0.923 \\
\hline \multicolumn{6}{|l|}{ Gender } \\
\hline Male & $31(31)$ & $27(27)$ & 1.215 & $0.659-2.240$ & 0.64 \\
\hline Female & $69(69)$ & $73(73)$ & & & \\
\hline \multicolumn{6}{|l|}{ Level of education } \\
\hline$<$ Secondary & $19(19)$ & $9(9)$ & 2.372 & $1.016-5.536$ & 0.067 \\
\hline$\geq$ Secondary & $81(81)$ & $91(91)$ & & & \\
\hline \multicolumn{6}{|l|}{ Marital status } \\
\hline Single (+divorced/widow) & $69(69)$ & $54(54)$ & 1.896 & $1.064-3.380$ & 0.042 \\
\hline Married (+concubinage) & $31(31)$ & $46(46)$ & & & \\
\hline \multicolumn{6}{|l|}{ Occupation } \\
\hline Employed & $53(53)$ & $58(58)$ & 0.817 & $0.467-1.427$ & 0.569 \\
\hline Unemployed & $47(47)$ & $42(42)$ & & & \\
\hline Having Health Insurance & $8(8)$ & $10(10)$ & 0.783 & $0.295-2.073$ & 0.805 \\
\hline Patients who drink alcohol & $79(79)$ & $70(70)$ & 1.612 & $0.847-3.069$ & 0.194 \\
\hline Patients who Smoke & $11(11)$ & $4(4)$ & 2.699 & $0.911-9.655$ & 0.107 \\
\hline Median Monthly income (USD) & $85.5(0-239.3)$ & $111.1(0-341.8)$ & & & 0.07 \\
\hline Mean Number of people/house & $3 \pm 2$ & $3 \pm 1$ & & -0.86 & 0.185 \\
\hline \multicolumn{6}{|l|}{ Family information } \\
\hline $\begin{array}{l}\text { Status is known by a family } \\
\text { member }\end{array}$ & $22(22)$ & $52(52)$ & 0.26 & $0.141-0.481$ & 0 \\
\hline Other family members are HIV+ & $2(2)$ & $5(5)$ & 0.388 & $0.073-2.047$ & 0.445 \\
\hline \multicolumn{6}{|l|}{ Partner's status } \\
\hline $\mathrm{HIV}+(\mathrm{n}=54)$ & $28(51.9)$ & $26(48.1)$ & 1.107 & $0.593-2.067$ & 0.873 \\
\hline HIV + and on treatment & $25(53.2)$ & $22(46.8)$ & 1.136 & $0.254-5.091$ & 1 \\
\hline $\begin{array}{l}\text { Mean Amount spent per health } \\
\text { consultation (USD) }\end{array}$ & $8.54 \pm 25.1$ & $5.98 \pm 0.59$ & & -5808.026 & 0.014 \\
\hline $\begin{array}{l}\text { Median Distance to health facility } \\
\text { (KM) }\end{array}$ & $7.5(5.0-12.0)$ & $5.0(4.0-7.0)$ & & & 0 \\
\hline Accessible patients & $87(46.8)$ & $99(53.2)$ & 0.068 & $0.009-0.527$ & 0.002 \\
\hline
\end{tabular}

(5-12) $\mathrm{km}$ is associated with LTFU compared to an average of 5 (4-7) km.

Furthermore, the context of HIV diagnosis, the mean BMI, medication side effects, development of opportunistic infections, taking treatment for other health conditions, duration of psychosocial follow-up, number of adherence counseling sessions, and the patient enrolment and participation in a support group was also associated with loss to follow-up.

The data also shows that $92 \%$ of No-LTFU patients are diagnosed during a clinical visit, compared to the $73 \%$ LTFU (OR-0.235, p-value-0.001) evidence that diagnosis at a clinical visit is a factor that reduces the frequency of LTFU. Moreso, an average $\mathrm{BMI}$ of $25.8 \pm 4.1$; a longer duration of psychosocial follow-up ( $p$-value-0.000); a larger number of adherence counseling sessions ( $p$-value-0.000), and enrolment of the patient in a support group (OR-0.191; P-value-0.000) are factors that significantly reduce the frequency of LTFU. Contrarily, drug side effects (OR-3.083; P-value -0.000); presence of opportunistic infections (OR-4,750; P-value-0.003) are factors that are associated with LTFU (Tables 4).

\section{Multivariate analysis}

On multivariate analysis: the long distance from the health facility $(O R=1.218 ;$ P-value $=0.022)$; occurrence of opportunistic infections $(\mathrm{OR}=14.744 ; \mathrm{P}$-value $=0.042)$; patient receiving concurrent treatment for other health conditions $(O R=30.096 ;$ P-value $=0.025)$; are factors that significantly expose patients to LTFU. The duration of psychosocial followup $(O R=0.956 ; p$-value $=0.036)$ and number of routine adherence counselling sessions $(O R=0.095 ; p$-value $=0.000)$ were found to be independently protective against being loss to follow-up (Table 5).

\section{Discussion}

Following the targets set (90-90-90) by the Joint United Nations Programme on HIV and AIDS, it was required that $90 \%$ of patients living with HIV are diagnosed, $90 \%$ of positive patients are placed on treatment and $90 \%$ of those on treatment achieve viral load suppression [1]. The last two targets are affected by the discontinuation of treatment and LTFU.

This study was aimed at identifying the determinants of loss to follow-up amongst patients attending the HIV clinic at the Centre Hospitalier Essos by comparing a case and a control group of 100 patients each.

There was a larger number of female patients recruited as cases and matched as controls. This could be explained by the fact that there is an increased possibility of stigmatization 
Citation: Agbor AN, Gael BAI, Brian A, et al. (2021) Predictors of Loss to Follow-up in Patients on Antiretroviral Treatment in Centre Hospitalier Essos, Cameroon. Clin J HIV AIDS 5(1):62-69

Table 4: Bivariate analysis of Factors in clinical history and treatment factors $(\mathrm{N}=200)$

\begin{tabular}{|c|c|c|c|c|c|}
\hline Variable & LTFU $(n=100) n(\%)$ & No LTFU $(n=100) n(\%)$ & OR & $\mathrm{Cl}$ & p-value \\
\hline \multicolumn{6}{|l|}{ Context of diagnosis } \\
\hline Clinical visit & $73(73)$ & $92(92)$ & 0.235 & $0.101-0.548$ & 0.001 \\
\hline Voluntary Counselling and Testing & $27(27)$ & $8(8)$ & & & \\
\hline \multicolumn{6}{|l|}{ Eligibility criteria for initiation } \\
\hline Clinical presentation + CD4 & $79(79)$ & $73(73)$ & 1.391 & $0.724-2.673$ & 0.408 \\
\hline Test and treat & $21(21)$ & $27(27)$ & & & \\
\hline \multicolumn{6}{|l|}{ WHO stage } \\
\hline Stage I and II & $58(58)$ & $71(71)$ & 0.564 & $0.314-1.014$ & 0.076 \\
\hline Stage III and IV & $42(42)$ & $29(29)$ & & & \\
\hline Mean BMI & $24.3 \pm 4.2$ & $25.8 \pm 4.1$ & & 1.105 & 0.01 \\
\hline \multicolumn{6}{|l|}{ Place of treatment initiation } \\
\hline Same facility & 99 (99) & $98(98)$ & 2.02 & $0.180-22.645$ & 1 \\
\hline Different facility & $1(1)$ & $2(2)$ & & & \\
\hline Median CD4 count at initiation & $298(153-438)$ & $298(165-405)$ & & & 0.808 \\
\hline Median First viral load & $316(60-3,124)$ & $166(60-700)$ & & & 0.147 \\
\hline Median Last viral load $(n=11)$ & $795(45-7,474)$ & $40(440-40)$ & & & 0.376 \\
\hline \multicolumn{6}{|l|}{ Treatment line } \\
\hline First-line treatment & $97(97)$ & $100(100)$ & & & 0.246 \\
\hline Second-line treatment & $3(3)$ & $0(0.0)$ & & & \\
\hline Mean Number of doses per day & $1 \pm 1$ & $1 \pm 1$ & & -0.262 & 1 \\
\hline Reported side effects & $52(52)$ & $26(26)$ & 3.083 & $1.701-5.588$ & 0 \\
\hline Opportunistic infections & $20(20)$ & $5(5)$ & 4.75 & $1.706-13.227$ & 0.003 \\
\hline Other treatment & $21(21)$ & $8(8)$ & 3.057 & $1.283-7.282$ & 0.016 \\
\hline Median Duration of psychosocial follow-up & $19.5(9.5-31.5)$ & $33.0(22.0-51.0)$ & & & 0 \\
\hline $\begin{array}{l}\text { Mean Number of routine adherence } \\
\text { counseling sessions }\end{array}$ & $3 \pm 1$ & $5 \pm 2$ & & -0.787 & 0 \\
\hline Patient enrolment in a support group & $14(14)$ & $46(46)$ & 0.191 & $0.096-0.380$ & 0 \\
\hline
\end{tabular}

Table 5: Multivariate analysis $(\mathrm{N}=200)$

\begin{tabular}{|c|c|c|c|c|c|}
\hline Variable & LTFU (n=100) n(\%) & No LTFU (n=100) n(\%) & OR & $\mathrm{Cl}$ & p-value \\
\hline < Secondary education & $19(19)$ & $9(9)$ & 8.301 & $0.573-120.290$ & 0.121 \\
\hline Marital status single & $69(69)$ & $54(54)$ & 1.819 & $0.398-8.313$ & 0.44 \\
\hline Alcohol consumption & $79(79)$ & $70(70)$ & 0.436 & $0.075-2.553$ & 0.358 \\
\hline Tobacco consumption & $11(11)$ & $4(4)$ & 0.388 & $0.025-5.942$ & 0.497 \\
\hline Median monthly income (USD) & $85.5(0-239.3)$ & $111.1(0-341.8)$ & 1 & $1.000-1.000$ & 0.227 \\
\hline Status not known by a family member & $78(78)$ & $48(48)$ & 4.027 & $0.585-27.748$ & 0.157 \\
\hline $\begin{array}{l}\text { Mean amount spent per consultation } \\
\text { (USD) }\end{array}$ & $8.54 \pm 25.1$ & $5.98 \pm 0.59$ & 1.006 & $0.117-8.629$ & 0.995 \\
\hline Distance to health facility $(\mathrm{Km})$ & $7.5(5.0-12.0)$ & $5.0(4.0-7.0)$ & 1.218 & $1.029-1.442$ & 0.022 \\
\hline Patient not accessible & $13(13)$ & $1(1)$ & 1.081 & $0.055-21.379$ & 0.959 \\
\hline Diagnosed by VCT & $27(27)$ & $8(8)$ & 10.849 & $0.990-118.869$ & 0.051 \\
\hline WHO stage $>$ II & $42(42)$ & $29(29)$ & 0.598 & $0.140-2.556$ & 0.488 \\
\hline Mean BMI (kg/m²) & $24.3 \pm 4.2$ & $25.8 \pm 4.1$ & 0.969 & $0.822-1.143$ & 0.711 \\
\hline First viral load (copies/ml) & $316(60-3,124)$ & $166(60-700)$ & 1 & $1.000-1.000$ & 0.173 \\
\hline Drug side effects & $52(52)$ & $26(26)$ & 2.124 & $0.440-10.248$ & 0.348 \\
\hline Occurrence of opportunistic infections & $20(20)$ & $5(5)$ & 14.744 & $1.099-197.773$ & 0.042 \\
\hline Patient on other treatment & $21(21)$ & $8(8)$ & 30.096 & $1.548-585.208$ & 0.025 \\
\hline $\begin{array}{l}\text { Median duration of psychological follow- } \\
\text { up (months) }\end{array}$ & $19.5(9.5-31.5)$ & $33.0(22.0-51.0)$ & 0.956 & $0.917-0.997$ & 0.036 \\
\hline $\begin{array}{l}\text { Mean number of Therapeutic education } \\
\text { sessions }\end{array}$ & $3 \pm 1$ & $5 \pm 2$ & 0.095 & $0.031-0.287$ & 0 \\
\hline Patient not in a support group & $14(14)$ & $46(46)$ & 6.768 & $0.994-31.880$ & 0.051 \\
\hline
\end{tabular}


associated with the female gender compared to their male counterparts and also that most of these women depend on their male partners for funding for payment of user fees in this treatment center. This trend is similar though higher than findings in Ethiopia whereby the female population accounted for just below $60 \%$ of the patients LTFU [11].

Distance from the patient's home to the health facility was one of the factors found to be independently associated with loss to follow-up in this study. It is without doubt therefore that patient's residing far from this treatment center have several associated barriers to access care and pick-up their medications ranging from extra financial commitments (transport to pick-up drugs considering the very lowincome ranges) and extra motivational commitments (difficult terrains as most of these areas more than $5 \mathrm{~km}$ from the treatment center are in the suburbs with difficult accessibility). Most of these patients have to use local means of transportation including taxis, commercial motorcycles, and commercial buses to get to the treatment center which all have an attached cost. Due to this, patients living further from the HIV treatment center are more likely to abandon their treatment compared to those residing closer to the treatment center. These findings are similar to those found in other parts of Cameroon: Nkongsamba [9] and in Limbe [7]. These are also similar to findings found in Uganda [12,13] and Botswana [14]. As a result, these clients must be transferred to treatment centers closer to their homes. Furthermore, they should benefit from differentiated care models such as home dispensation, community ART dispensation, and multi month dispensation if they choose to pursue treatment in this treatment center.

Furthermore, the occurrence of an opportunistic infection predisposed the patients to be lost to follow-up. Opportunistic infections are usually associated with a weak immunological state which is usually reflected by a poor physical state. As a result, most of these patients will be physically very ill and even bedridden and this could explain their inability to go to the treatment centers to collect their medications. Furthermore, with opportunistic infections like tuberculosis and toxoplasmosis, there are many pills to be taken daily, in addition to the ARV pills. This large number of pills may be a turn-off for most patients who could decide to abandon their ART hence become LTFU (pill effect/burden). Again, there is an increased possibility of the occurrence of adverse drug effects and drug-drug interactions between ARVs and medications used to treat these opportunistic infections which could enable LTFU. Similar findings were made in Ethiopia [11], Gabon [15], Togo [16], and Uganda [17].

The psychosocial follow-up of patients is an important aspect and an important component of the care package of HIV-positive patients. The longer the psychosocial follow-up, the stronger the confidence built between the psychosocial agents and the patients. Furthermore, patients who have longer psychosocial follow-up have a better understanding of disease pathway, drug side effects, and the importance of drug adherence compared to patients with a shorter psychosocial follow-up. This could explain the disparities concerning LTFU. This is similar to findings in Vietnam [18].
Strengthening of psychosocial support to HIV patients has been one of the key areas of intervention in reducing LTFU. In South Africa and Malawi, peer-led psychosocial support has been used to reduce LTFU especially amongst pregnant women [19]. Peer-led psychosocial support could greatly improve both adherence and retention and will be a great strategy to try out in adult care in Cameroon.

Routine adherence counseling sessions attended influenced significantly whether a patient could become LTFU or not. Adherence counseling sessions are very important as they provide a forum to evaluate the patient's adherence to treatment, reinforcing treatment adherence, identify barriers to treatment, and eliminate such barriers to treatment adherence. It could therefore be stated that adherence counseling sessions directly influence patient adherence to treatment. The more frequent the adherence counseling sessions, the more adherent the patient will be to treatment hence this could explain the differences in LTFU associated with different numbers of adherence counseling sessions. Furthermore, in Ivory Coast, due to large rates of LTFU, there was a reinforcement of patient home visits. These visits at the home of patients were carried out by health care workers and peer workers and included continuous counseling and education on HIV treatment adherence to the patients and their families [20]. Again, information systems and information technology have been used as an innovative approach to improving patient adherence, respect of routine clinical visits, and hence reduce LTFU in Malawi and Rwanda [21]. These models will probably improve ART adherence and reduce LTFU in the Cameroonian setting.

Furthermore, the knowledge of the HIV status by a family member was not significant but remains essential to long-term adherence to ARV. Family support constitutes an important factor to patient adherence and hence decreasing loss to follow-up.

This study had several limitations. First, due to the study design, some variables could not be evaluated which could contribute significantly to LTFU as highlighted in other studies. These variables include stigma and mental status/ depression. Furthermore, the findings cannot be generalized to other hospital categories (level 3, 4, 5, and 6 hospitals) such as health centers and district hospitals which may have a different functional and organizational structure. Again, the outcome of the patients LTFU could not be known from this study (dead, transferred to other facilities, brought back to care, and others). Finally, the quality of service provided at the treatment center which could influence accessibility was not investigated in this study.

\section{Conclusion}

The targets set for each of the countries for the management of HIV/AIDS by UNAIDS are ambitious but can be attained. However, LTFU remains one of the main challenges to attaining the last two targets. With LTFU, there is a consequent increased risk of HIV transmission and also increased morbidity and mortality. This study identified distance to the health facility, occurrence of opportunistic infections, patient receiving concurrent 
treatment for other conditions, duration of psychological follow-up, and the number of adherence counseling sessions to be independently associated with loss to follow-up. Interventions to address these factors should be implemented to optimize patient care and ameliorate the overall HIV program cascade nationwide. Some recommendations include the reinforcement of adherence counseling sessions with appropriate documentation in patient records. Routine adherence counseling should systematically be done at each patient-healthcare provider encounter. Furthermore, the use of peer-led adherence counseling could add value to counseling sessions; Home visits should be intensified and home counseling should involve reinforcement of family support and reinforcement of treatment adherence; Early diagnosis and treatment of patients to avoid the occurrence of opportunistic infections; Intensification of patient tracking especially for patients with comorbidities; Transfer of patients in suburbs to health facilities closer to their areas of residence. Finally, appropriate differentiated models of care should be used on a patient-to-patient basis to improve treatment adherence and retention.

\section{References}

1. UNAIDS (2018) Global report: UNAIDS report on the global AIDS epidemic 2018.

2. Lawn SD, Harries AD, Anglaret X, et al. (2008) Early mortality among adults accessing antiretroviral treatment programmes in sub-Saharan Africa. AIDS 22: 1897-908.

3. CAMPHIA (2018) Cameroon Population-Based HIV Impact Assessment Camphia 2017. Summary sheet: Preliminary Findings.

4. NIS (2011) Enquête Démographique et de Santé et à Indicateurs Multiples EDS-MICS 2011 Rapport Préliminaire sur la prévalence du VIH. Yaounde.

5. Tsague L, Koulla SS, Kenfak A, et al. (2008) Determinants of retention in care in an antiretroviral therapy (ART) program in urban Cameroon, 2003-2005. Pan African Medicine Journal 1: 2.

6. Rougemont M, Stoll BE, Elia N, et al. (2009) Antiretroviral treatment adherence and its determinants in Sub-Saharan Africa: A prospective study at Yaounde Central Hospital. Cameroon AIDS Research and Therapy 6: 21-10.

7. Mosoko JJ, Akam W, Weidle PJ, et al. (2011) Retention in an antiretroviral therapy programme during an era of decreasing drug cost in Limbe, Cameroon. Journal J Int AIDS Soc 10: 14-32.

8. Assefa Y, Kiflie A, Tesfaye D, et al. (2011) Outcomes of antiretroviral treatment program in Ethiopia: retention of patients in care is a major challenge and varies across health facilities. BMC Health Serv Res 11: 81.
9. Bekolo CE, Webster J, Batenganya M, et al. (2013) Trends in mortality and loss to follow-up in HIV care at the Nkongsamba Regional hospital, Cameroon. BMC Research Notes 2013 6:512.

10. https://www.openepi.com/SampleSize/SSCC.htm

11. Gesesew HA, Ward P, Woldemichael K, et al. (2017) Prevalence, trend, and risk factors for antiretroviral therapy discontinuation among HIV-infected adults in Ethiopia in 2003-2015. PLoS One 12: e0179533.

12. Tuller DM, Bangsberg DR, Senkungu J, et al. (2010) Transportation costs impede sustained adherence and access to HAART in a clinic population in southwestern Uganda: a qualitative study. AIDS Behaviour 14: 778-784.

13. Senkomago V, Guwatudde D, Breda M, et al. (2011) Barriers to antiretroviral adherence in HIV-positive patients receiving free medication in Kayunga, Uganda. AIDS Care 23: 1246-1253.

14. Weiser S, Wolfe W, Bangsberg D, et al. (2003) Barriers to antiretroviral adherence for patients living with HIV infection and AIDS in Botswana. J Acquir Immune Defic Syndr 34: 281288.

15. Janssen S, Wieten RW, Stolp S, et al. (2015) Factors associated with retention to care in an HIV clinic in Gabon, Central Africa. PLOS ONE 10: e0140746.

16. Saka B, Landoh DE, Patassi A, et al. (2013) Loss of HIV-infected patients on potent antiretroviral therapy programs in Togo: risk factors and the fate of these patients. Pan Afr Med J 15: 35.

17. Asiimwe S, Kanyesigye M, Bwana B, et al. (2016) Predictors of dropout from care among HIV-infected patients initiating antiretroviral therapy at a public sector HIV treatment clinic in sub-Sharan Africa. BMC Infectious Diseases 16: 43.

18. Tran DA, Ngo AD, Shakeshaft A, et al. (2013) Trends in and determinants of loss to follow up and early mortality in a rapid expansion of the antiretroviral treatment program in Vietnam: Findings from 13 outpatient clinics. PLoS ONE 8: e73181.

19. Baek C, Rutenberg N (2010) Looking backward, moving forward: implementing PMTCT programs in resource-constrained settings, Horizons studies. 1999-2007. Horizons Synthesis Background Papers, Population Council, Washington, DC, USA.

20. Tonwe-Gold B, Ekouevi DK, Amani-Bose C (2009) Implementing family-focused HIV care and treatment: the first 2 years experience of the mother-to-child transmission-plus program in Abidjan, Cote d'Ivoire. Tropical Medicine and International Health 14:204-212.

21. Fraser HSF, Allen C, Bailey C, et al. (2007) Information systems for patient follow-up and chronic management of HIV and tuberculosis: A life-saving technology in resource-poor areas. Journal of Medical Internet Research 9: e29.

DOI: $10.36959 / 695 / 573$

Copyright: (C) 2021 Agbor AN. This is an open-access article distributed under the terms of the Creative Commons Attribution License, which permits unrestricted use, distribution, and reproduction in any medium, provided the original author and source are credited. 